\title{
Características produtivas e estruturais do milheto e sua relação com o ganho de peso de bezerras sob suplementação alimentar
}

\author{
Juliano Roman ${ }^{1}$, Marta Gomes da Rocha ${ }^{2}$, Teresa Cristina Moraes Genro ${ }^{3}$, Davi Teixeira dos \\ Santos $^{1}$, Fabiana Kellermann de Freitas ${ }^{1}$, Denise Baptaglin Montagner ${ }^{1}$
}

\footnotetext{
1 Programa de Pós-Graduação em Zootecnia, Universidade Federal de Santa Maria, Santa Maria - RS

2 Departamento de Zootecnia, Universidade Federal de Santa Maria, Santa Maria - RS.

${ }^{3}$ Embrapa Pecuária Sul, Bagé - RS.
}

\begin{abstract}
RESUMO - Foram avaliadas características produtivas e estruturais do milheto (Pennisetum americanum (L.) Leeke) sob pastejo em lotação contínua e sua relação com o desempenho de bezerras exclusivamente em pastejo (PAST) ou sob suplementação com grão de milho $(\mathrm{PAST}+\mathrm{M})$ ou polpa cítrica $(\mathrm{PAST}+\mathrm{P})$. Não houve diferença entre tratamentos para a massa e oferta de forragem, a massa e oferta de lâminas foliares, a taxa de acúmulo diário e a produção total de forragem. A taxa de acúmulo diário de forragem, a massa e a oferta de lâminas foliares diminuíram linearmente durante o período de pastejo A participação dos componentes de milheto na estrutura do dossel foi similar entre tratamentos e variou no tempo. A suplementação energética promoveu aumento da taxa de lotação no período inicial de pastejo, quando houve alta participação de lâminas foliares no dossel, e do ganho de peso médio diário nos períodos subseqüentes, quando houve redução da participação de lâminas foliares. Em pastagem de milheto, a resposta à suplementação energética varia com a quantidade e a distribuição de lâminas foliares no dossel. O fornecimento de suplemento energético aos animais em pastejo não interfere nas características produtivas e estruturais do milheto.
\end{abstract}

Palavras-chave: estrutura do dossel, ganho médio diário, lâminas foliares, produção de forragem, suplementação energética, taxa de lotação

\section{Productive and structural characteristics of Pearl millet and their relationship with body weight gain of beef heifers receiving supplement}

\begin{abstract}
The productive and structural characteristics of Pearl millet (Pennisetum americanum (L.) Leeke) under continuous stocking rate and their relationship with beef heifers performance exclusively under grazing (PAST), supplemented with corn grain $(\mathrm{PAST}+\mathrm{C})$ or citric pulp $(\mathrm{PAST}+\mathrm{P})$ was evaluated. There was no difference among treatments for herbage mass, forage allowance, leaf lamina mass, leaf lamina allowance, daily accumulation rate of forage and herbage total production. Daily accumulation rate of forage, leaf lamina mass and leaf lamina allowance decreased linearly during the grazing period. The participation of Pearl millet components in the sward structure was similar among treatments and changed during the time. The energetic supplementation increased the stocking rate at beginning of grazing, with high leaf lamina participation in the canopy and increased the average daily gain in subsequent periods, with decreasing of the leaf lamina participation. The effect of energetic supplementation on Pearl millet pasture is linked with the amount and distribution of leaf lamina in the canopy structure. The energetic supplementation does not affect the structural and productive characteristics of pearl millet.
\end{abstract}

Key Words: average daily gain, canopy structure, energetic supplementation, herbage production, leaf blade, stocking rate

\section{Introdução}

A bovinocultura de corte brasileira tem se destacado no cenário internacional, como resultado do aumento expressivo de sua participação no comércio mundial de carne bovina. Apesar do aumento nos índices zootécnicos, a produtividade média do rebanho nacional continua aquém de seu potencial.
Entre os índices produtivos do sistema pecuário, a taxa de natalidade tem grande importância. Considerando as ferramentas disponíveis para melhoria da taxa de natalidade, a desmama de bezerros aos 60-90 dias de idade é uma técnica importante e eficaz e que proporciona benefício direto nas taxas de repetição de prenhez e natalidade, independentemente do manejo alimentar das vacas na fase pós-desmama de seus bezerros (Santos et al., 2004). 
A alimentação dos bezerros(as) desmamados(as) nessa idade, no entanto, deve ser bem estudada, pois deve-se assegurar a esses animais desenvolvimento semelhante ao que seria obtido se continuassem amamentados. $\mathrm{O}$ uso exclusivo de pastagens nesta fase pode representar o sistema de maior economicidade, no entanto, existem dúvidas se espécies forrageiras de clima tropical, como o milheto (Pennisetum americanum (L.) Leeke), quando utilizadas de forma exclusiva, podem suprir todos os nutrientes necessários para o desenvolvimento adequado desses animais sem prejudicar seu crescimento.

No Rio Grande do Sul, por sua produtividade e seu valor nutritivo, o milheto é uma das mais importantes opções forrageiras para a alimentação de bovinos na estação quente. A disponibilidade de nutrientes no pasto, no entanto, não é uniforme durante seu ciclo e modificações na estrutura da planta podem interferir no pastejo dos animais (Coser \& Maraschin, 1983; Pilau et al., 2004).

O uso de suplementação energética em pastagens de alto valor nutritivo, como o milheto, é uma forma de garantir melhor balanceamento da dieta e aumento no consumo de matéria seca (MS), com incremento no desempenho individual e na capacidade de suporte das pastagens. A resposta dos animais em pastejo à suplementação pode variar com as características da pastagem, o manejo adotado (Prache et al., 1990; Pilau et al., 2005) ou o ciclo da planta (Pilau et al., 2004). Além disso, a suplementação pode influenciar o comportamento ingestivo (Bremm et al., 2005), a seletividade dos animais e as características da pastagem (Frizzo et al., 2003; Rocha et al., 2004).

Este trabalho foi realizado com o objetivo de avaliar as características produtivas e estruturais de pastagem de milheto (Pennisetum americanum (L.) Leeke) e sua relação com o desempenho de bezerras de corte desmamadas aos 60-90 dias de idade recebendo ou não suplementação energética.

\section{Material e Métodos}

O experimento foi conduzido em área do Departamento de Zootecnia da Universidade Federal de Santa Maria, localizada na Depressão Central do Rio Grande do Sul, com altitude de $95 \mathrm{~m}$, latitude $29^{\circ} 43^{\prime}$ sul e longitude $53^{\circ} 42^{\prime}$ oeste.

O solo da área experimental é classificado como Argissolo Vermelho Distrófico Arênico (EMBRAPA, 1999) e pertence à unidade de mapeamento São Pedro; apresenta relevo levemente ondulado, com solos profundos e textura superficial arenosa, bem drenados e naturalmente ácidos. $\mathrm{Na}$ análise do solo da área experimental, foram obtidos os seguintes resultados: $\mathrm{pH}-\mathrm{H}_{2} \mathrm{O}: 4,4 ; \%$ argila: $23 \mathrm{~m} / \mathrm{V}$; P: 9,0 mg/L; K: 62,0 mg/L; \% MO: 2,7 m/V; Al: 2,4 cmol/L; Ca: $1,7 \mathrm{cmol} / \mathrm{L} ; \mathrm{Mg}: 0,6 \mathrm{cmol} / \mathrm{L} ; \mathrm{CTC} \mathrm{pH} 7: 10,4$.

$\mathrm{O}$ clima da região é $\mathrm{Cfa}$ (subtropical úmido) conforme classificação de Köppen (Moreno, 1961). As médias mensais de temperatura máxima e mínima diária, precipitação pluviométrica e insolação observadas durante o período experimental constam na Tabela 1 .

Avaliou-se a utilização de dois suplementos energéticos para animais em pastagem de milheto (Pennisetum americanum (L.) Leeke). Os tratamentos testados foram: PAST - animais em pastagem de milheto, sem suplementação; $\mathrm{PAST}+\mathrm{M}$ - animais em pastagem de milheto recebendo suplementação com grão de milho moído; PAST + PC animais em pastagem de milheto recebendo suplementação com polpa cítrica peletizada e moída. O teor de proteína bruta (PB) dos suplementos utilizados foi analisado previamente ao experimento, sendo corrigido com uréia para $12 \% \mathrm{~PB}$.

A área experimental totalizou 5,8 ha com seis subdivisões de 0,7 ha, que constituíram as unidades experimentais (piquetes), mais uma área anexa de 1,6 ha para alojar animais reguladores da massa de forragem (MF). A semeadura do milheto foi feita a lanço, em 3/1/2001, em solo previamente preparado com duas gradagens, uma pesada e outra leve. Utilizaram-se $35 \mathrm{~kg} / \mathrm{ha}$ de sementes de milheto e $200 \mathrm{~kg} / \mathrm{ha}$ da fórmula 05-20-20 como adubação de semeadura. A adubação de cobertura foi realizada com $150 \mathrm{~kg} / \mathrm{ha}$ de nitrogênio (N), na forma de uréia, parcelada em duas aplicações: 20/2 e 30/3. O período de utilização da pastagem totalizou 63 dias, entre $16 / 2$ e $20 / 4$.

Foram utilizadas bezerras mestiças resultantes de cruzamentos entre as raças Charolês, Nelore, Hereford e Angus, com 100 dias de idade, $95,5 \pm 10,0 \mathrm{~kg}$ de peso vivo e condição corporal inicial de $2,9 \pm 0,2$. Os animais foram agrupados em três lotes uniformes quanto ao tipo racial, distribuídos ao acaso nos tratamentos. Utilizaram-se quatro bezerras-teste por unidade experimental.

Tabela 1 - Médias mensais de temperatura, precipitação pluviométrica e insolação no período de janeiro a abril de $2001^{1}$

\begin{tabular}{lcccc}
\hline Mês & \multicolumn{2}{c}{$\begin{array}{c}\text { Temperatura } \\
\left({ }^{\circ} \mathrm{C}\right)\end{array}$} & $\begin{array}{c}\text { Precipitação } \\
\text { pluviométrica }(\mathrm{mm})\end{array}$ & $\begin{array}{c}\text { Insolação } \\
\text { (horas })\end{array}$ \\
\cline { 2 - 3 } & Máxima & Mínima & & \\
\hline Janeiro & 30,0 & 20,7 & 309,9 & 164,6 \\
Fevereiro & 31,3 & 22,0 & 124,8 & 171,6 \\
Março & 30,3 & 20,7 & 144,1 & 191,3 \\
Abril & 22,7 & 17,1 & 249,6 & 138,9 \\
\hline
\end{tabular}

${ }^{1}$ Fonte: Estação metereológica da UFSM. 
O método de pastejo foi o de lotação contínua, com número variável de animais pela técnica put and take (Mott \& Lucas, 1952). Foram utilizados animais da mesma categoria como reguladores da massa de forragem (MF). O ajuste da lotação foi feito semanalmente, por meio de avaliações visuais da MF e considerando valores estimados da taxa de acúmulo diário de forragem, visando manter a MF em $1.800 \mathrm{a} 2.000 \mathrm{~kg} / \mathrm{ha}$ de MS. Os suplementos foram fornecidos diariamente às $8 \mathrm{~h} 30$ em quantidade correpondente a 0,9\% do PV, com base na MS.

As avaliações do pasto e dos animais foram realizadas no início e ao final de cada período de 21 dias. A determinação de MF ( $\mathrm{kg} / \mathrm{ha}$ MS) foi feita utilizando-se a técnica de dupla amostragem (Wilm, 1944), com 20 amostragens visuais e cinco amostras cortadas rente ao solo em área de $0,25 \mathrm{~m}^{2}$. Em cada unidade experimental, coletaram-se cinco amostras que, depois de homogeneizadas, constituíram uma nova amostra, a qual foi utilizada para determinação do teor de MS.

A estimativa da taxa de acúmulo diário de forragem (TAD, $\mathrm{kg} / \mathrm{ha} / \mathrm{dia} \mathrm{MS}$ ) foi realizada utilizando-se três gaiolas de exclusão ao pastejo por unidade experimental (Klingmann et al., 1943). A produção total de forragem (PMS, $\mathrm{kg} / \mathrm{ha} \mathrm{de}$ MS) foi calculada como o somatório das produções dos períodos experimentais, estimada pela TAD mais a MF inicial.

Para a avaliação da estrutura vertical da pastagem, utilizaram-se três quadrados de $1 \mathrm{~m}^{2}$. A coleta das amostras foi realizada a cada 21 dias, em três pontos representativos da pastagem por unidade experimental. Foram avaliados os estratos de 0 a $15 \mathrm{~cm}$ (cortado rente ao solo), 15 a $30 \mathrm{~cm}$, 30 a $45 \mathrm{~cm}$ e acima de $45 \mathrm{~cm}$. Cada estrato foi cortado, acondicionado em sacolas plásticas e posteriormente separado manualmente em lâmina foliar, pseudocolmo (colmo + bainha foliar), material morto e inflorescência de milheto. Os valores foram expressos em porcentagem e em $\mathrm{kg} / \mathrm{ha} \mathrm{MS}$ e multiplicados pelo valor da MF.

As amostras coletadas para determinação de MS, TAD e composição estrutural do pasto foram mantidas em estufa de ar forçado a $65^{\circ} \mathrm{C}$, por 72 horas e pesadas.

Os animais foram pesados nos dias 16/2,10/3, 30/3 e $21 / 4$. Nas pesagens inicial e final, foram submetidos a jejum de 12 horas e, nas intermediárias, a jejum de 6 horas. O ganho de peso médio diário (GMD, $\mathrm{kg} / \mathrm{animal} / \mathrm{dia}$ ) dos animais em cada período experimental foi obtido pela diferença de peso entre as datas das pesagens dividido pela número de dias do período. A carga animal ( $\mathrm{kg} / \mathrm{ha}$ de PV) por período foi obtida pela soma do peso médio dos animais-teste acrescida da soma do peso médio dos animais reguladores multiplicado pelo número de dias em que foram mantidos na repetição e dividido pelo número de dias do período experimental. $\mathrm{O}$ valor obtido foi dividido por 450 para obtenção da taxa de lotação (TL), expressa em unidade animal (UA) por hectare.

A oferta diária de forragem (OF) foi calculada por meio da seguinte equação:

$\mathrm{OF}=((\mathrm{MF} /$ número de dias do período $)+\mathrm{TAD}) / \mathrm{CA}$, em que $C A$ refere-se à carga animal. Para cálculo da oferta de lâminas foliares (OLF), utilizou-se a seguinte equação: $\mathrm{OLF}=(((\mathrm{MF} /$ número de dias do período $)+\mathrm{TAD}) \times \%$ lâminas foliares)/CA. Em ambos os casos, os valores obtidos foram multiplicados por 100 e expressos em kg $\mathrm{MS} / 100 \mathrm{~kg}$ PV.

O delineamento experimental foi inteiramente casualizado em parcelas subdivididas no tempo, com três tratamentos, duas repetições e três períodos de avaliação. Para os dados de estrutura do pasto, foram consideradas parcelas subsubdivididas.

Os dados foram submetidos a análises de variância pelo General Linear Models Procedure (Proc GLM) e, quando detectadas diferenças entre as médias, aplicou-se o teste Tukey a 5\% de significância. Realizaram-se ainda teste de contrastes e análise de regressão das variáveis em função dos períodos de pastejo utilizando-se nível crítico de significância estatística de 5\%. Utilizou-se o pacote estatístico SAS (1996).

\section{Resultados e Discussão}

Não houve interação $(\mathrm{P}>0,05)$ tratamento $\times$ período para $\mathrm{MF}$ e oferta de forragem (OF), que não diferiram $(\mathrm{P}>0,05)$ entre os tratamentos (Tabela 2). Houve diferença $(\mathrm{P}<0,05)$ entre períodos na MF.

A adequação da taxa de lotação durante o experimento foi eficiente na manutenção da MF dentro dos valores pretendidos e semelhantes entre animais sob suplementação e aqueles exclusivamente em pastagem. A menor MF no terço inicial de pastejo foi ocasionada pelo baixo valor de MF no momento de entrada dos animais $(1.190,8 \mathrm{~kg} / \mathrm{ha} \mathrm{de}$ MS). Esse manejo foi imposto para permitir melhor perfilhamento e evitar o alongamento precoce de colmos do milheto.

A oferta média de forragem foi 3,8 vezes superior à exigência de ingestão de matéria seca (MS) de bezerras de corte aos $135 \mathrm{~kg}$ de peso vivo (2,7\% PV; NRC, 1984). A oferta de forragem média mantida neste experimento está dentro da amplitude mencionada por Hodgson (1981) de que o consumo de forragem é maximizado: 3 a 4 vezes a capacidade de ingestão de MS do ruminante. 
A taxa de acúmulo diária de forragem (TAD) e a produção total de forragem (PMS) de pastagem de milheto foram semelhantes $(\mathrm{P}>0,05)$ em todos os tratamentos (Figura 1) e não houve interação $(\mathrm{P}>0,05)$ tratamento $\times$ período para essas variáveis.

Houve diminuição linear da TAD com o avanço do período de pastejo, reflexo da diminuição do fotoperíodo e do início da diferenciação floral do milheto. A produção de forragem, de $7.077,6 \mathrm{~kg} / \mathrm{ha}$ de MS, ficou abaixo da obtida por outros autores com mesmo nível de nitrogênio (Moraes \& Maraschin, 1988; Lupatini et al., 1996; Heringer \& Moojen, 2002), fato atribuído ao menor período de utilização (63 dias). Mesmo assim, a produção de forragem foi superior à produção do campo nativo no Rio Grande do Sul em toda sua estação de crescimento (Moojen \& Maraschin, 2002), o que comprova o potencial produtivo do milheto mesmo quando utilizado no final do verão e início do outono.

Não houve interação $(\mathrm{P}>0,05)$ tratamento $\times$ período para massa e oferta de lâminas foliares, que não diferiram

Tabela 2 - Valores médios de massa de forragem (MF) e oferta de forragem (OF) em pastagem de milheto (P. americanum) ao longo do período de pastejo ${ }^{1}$

\begin{tabular}{lcc}
\hline Período de pastejo & $\begin{array}{c}\text { Massa de forragem } \\
(\mathrm{kg} / \mathrm{ha} \text { MS })\end{array}$ & $\begin{array}{c}\text { Oferta de forragem } \\
(\mathrm{kg} \text { MS/100 PV) }\end{array}$ \\
\hline $16 / 2-8 / 3$ & $1.608,8 \pm 249,7 \mathrm{~b}$ & $8,0 \pm 1,9$ \\
$9 / 3-30 / 3$ & $2.102,0 \pm 167,3 \mathrm{a}$ & $11,3 \pm 2,3$ \\
$31 / 3-21 / 4$ & $1.993,4 \pm 263,7 \mathrm{a}$ & $12,0 \pm 2,9$ \\
\hline Média & $1.901,4 \pm 307,3$ & $10,4 \pm 2,9$ \\
\hline $\mathrm{CV}(\%)$ & 10,7 & 30,3 \\
\hline
\end{tabular}

${ }^{1}$ Médias com letras minúsculas diferentes na mesma coluna diferem $(\mathrm{P}<0,05)$.

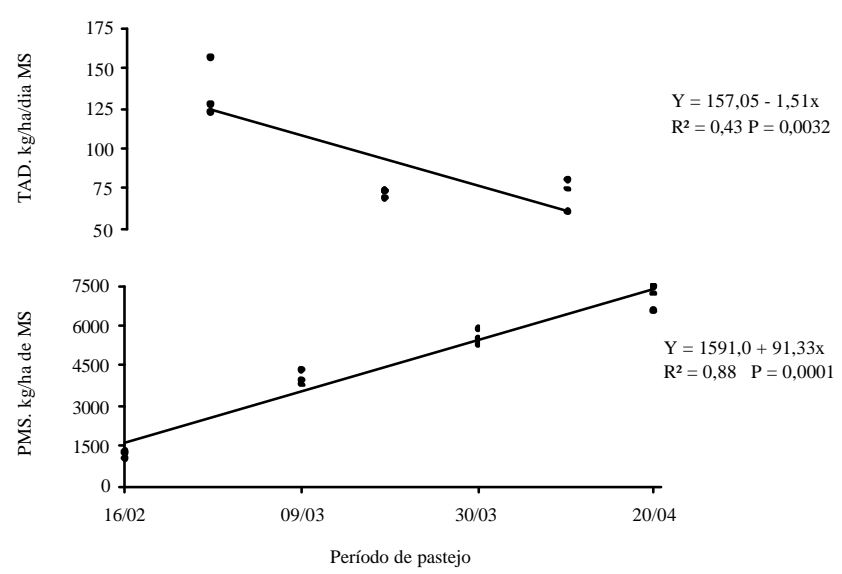

Figura 1 - Valores médios observados (pontos) e estimados (linhas) da taxa de acúmulo diário (TAD) e da produção total de forragem (PMS) de milheto ao longo do período de pastejo.
$(\mathrm{P}>0,05)$ entre os tratamentos (Figura 2). O uso da suplementação não promoveu alterações das características produtivas e estruturais do pasto, o que poderia ocorrer como resultado da influência na seletividade dos animais, conforme verificado por Frizzo et al. (2003) e Rocha et al. (2004).

Houve decréscimo linear diário na quantidade de lâminas foliares presentes no pasto e ofertada aos animais. Animais consomem quantidades maiores de folhas em relação a outras partes da planta, em virtude de sua menor resistência à quebra pela mastigação e do menor tempo de retenção no rúmen (Minson, 1990). Com o início do florescimento do milheto, período no qual a planta exporta a maioria dos assimilados para o desenvolvimento da inflorescência, houve redução do crescimento foliar (Gonçalves \& Quadros, 2003) e a reposição de tecido foliar não foi suficiente para compensar o desaparecimento de lâminas foliares consumidas pelos animais, o que refletiu em diminuição da participação deste componente na massa de forragem. A quantidade ofertada de lâminas foliares no final do período de pastejo ficou abaixo da exigência diária de ingestão de MS dos animais.

Além da quantidade de lâminas foliares presentes na pastagem e ofertada aos animais, deve-se considerar também sua distribuição na estrutura do dossel (Figura 3). Verificou-se interação $(\mathrm{P}<0,05)$ estrato do dossel $\times$ período de pastejo sobre os valores dos componentes lâmina foliar, pseudocolmo (colmo + bainha foliar), material morto e inflorescência de milheto presentes nos diferentes estratos verticais.

Os dados referentes ao componente lâmina foliar não se ajustaram aos modelos de regressão testados $(\mathrm{P}>0,05)$ no

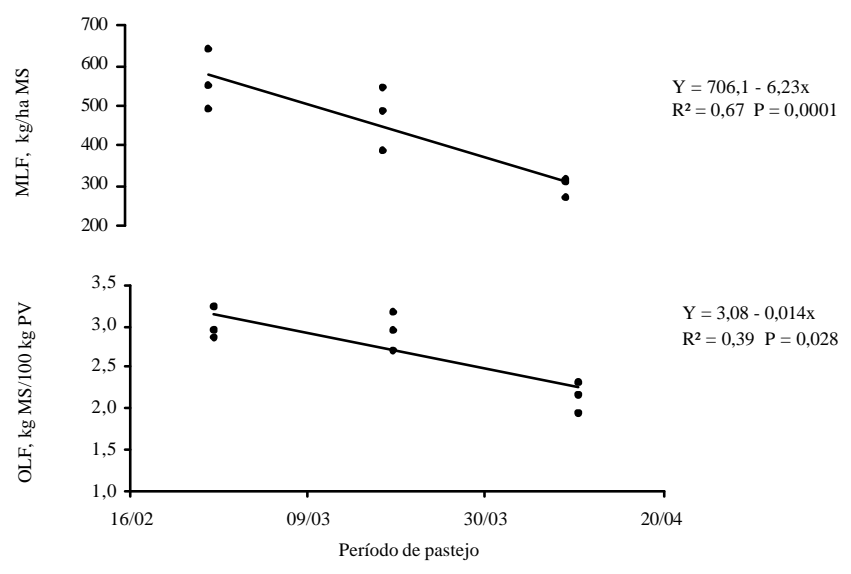

Figura 2 - Valores médios observados (pontos) e estimados (linha) de massa de lâminas foliares e oferta de lâminas foliares em pastagem de milheto ao longo do período de pastejo. 
estrato de 0 a $15 \mathrm{~cm}$, com média de $142,5 \mathrm{~kg} / \mathrm{ha}$ MS durante todo o período de pastejo. Nos demais estratos, 15 a $30 \mathrm{~cm}$, 30 a $45 \mathrm{~cm}$ e $+45 \mathrm{~cm}$, a quantidade de lâminas foliares diminuiu linearmente no transcorrer do ciclo do milheto. A diminuição da quantidade de lâminas foliares na estrutura da pastagem foi resultado do desaparecimento deste componente principalmente nos estratos acima de $30 \mathrm{~cm}$, provavelmente pela maior acessibilidade e preferência dos animais na colheita de lâminas foliares nos horizontes superficiais (Hodgson, 1990). A quantidade de lâminas foliares registrada nesses estratos representou $45,4 \%$ da massa total de lâminas foliares no início do pastejo e apenas $1,6 \%$ no final do experimento.

A quantidade de pseudocolmo no pasto apresentou aumento linear nos primeiros $15 \mathrm{~cm}$, chegando a representar no final do período de pastejo $28,5 \%$ da MF. Nos demais estratos, a quantidade de pseudocolmos ajustou-se ao modelo quadrático de regressão, com aumentos até o $32 \underline{0}$ dia para $15-30 \mathrm{~cm}$ e até o $27 \underline{\mathrm{o}}$ dia para $30-45 \mathrm{~cm}$ e $+45 \mathrm{~cm}$. A redução ocorrida a partir deste período pode ser atribuída à diferenciação floral e ao aparecimento de inflorescência. Além disso, com a diminuição da quantidade de lâminas foliares nos estratos superiores, pode ter havido consumo de pseudocolmos pelos animais.

A presença de material morto no estrato de 0 a $15 \mathrm{~cm}$ aumentou linearmente com o avanço do período de pastejo. No estrato de 15 a $30 \mathrm{~cm}$, a quantidade de material morto ajustou-se ao modelo quadrático, com aumento até o 35ㅇ dia. No estrato de 30 a $45 \mathrm{~cm}$, o componente material morto não se ajustou às equações de regressão testadas e apresentou participação média de 19,4 kg/ha de MS durante o período experimental. O mesmo ocorreu no estrato acima de $45 \mathrm{~cm}$, no qual a participação média de material morto durante o período de pastejo ficou em torno de $3,6 \mathrm{~kg} / \mathrm{ha}$ de $\mathrm{MS}$.

Houve aumento linear da participação de inflorescência nos estratos 0 a 15,15 a 30 e 30 a 45 cmcom seu aparecimento a partir de 9/3. No estrato acima de $45 \mathrm{~cm}$, não houve ajuste às equações testadas, com participação média de $6,8 \mathrm{~kg} / \mathrm{ha}$ de MS.

Por ocasião do início do pastejo, houve boa participação de lâminas foliares em ambos os estratos, pequena quantidade de colmos nos estratos superiores, e pequena participação de material morto. Essa estrutura foi modificando-se com o avanço do ciclo do milheto, com considerável aumento de material morto e pseudocolmos principalmente nos estratos inferiores, além da diminuição de lâminas foliares nos estratos superiores e do aparecimento de inflorescência em todos os estratos. O florescimento altera o desenvolvi-
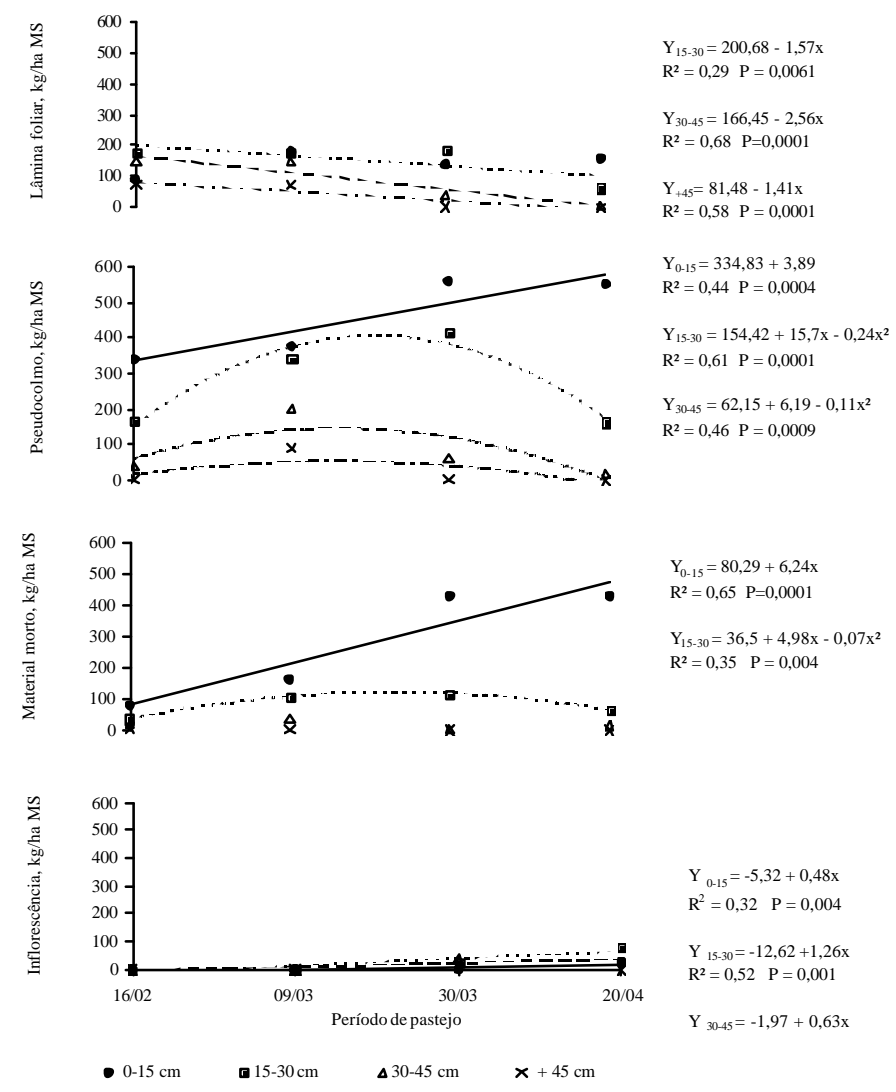

Figura 3 - Valores médios observados (pontos) e estimados (linhas) de lâminas foliares, pseudocolmos (colmo + bainha foliar), material morto e inflorescência nos diferentes estratos da pastagem de milheto ao longo do período de pastejo.

mento morfológico da planta e a relação folha:colmo, pois o crescimento de novas folhas é interrompido ao mesmo tempo em que o crescimento de colmos continua (Nelson \& Moser, 1994). Nos últimos 21 dias de pastejo, os estratos onde se concentraram lâminas foliares ( 0 a 15 e 15 a $30 \mathrm{~cm}$ ) caracterizaram-se também por altas quantidades de pseudocolmos e material morto.

Em razão da ausência de diferença $(\mathrm{P}>0,05)$ entre o ganho médio diário (GMD) e a taxa de lotação (TL) entre tratamentos com suplementação, os dados destas variáveis foram agrupados e procedeu-se apenas à análise de variância entre presença ou ausência de suplementação (Figura 4). Uma vez que os animais não foram submetidos a jejum prévio nas pesagens intermediárias, as variações dos tratamentos são discutidas somente dentro de cada período. Não houve interação $(\mathrm{P}>0,05)$ tratamento $\times$ período para a variável taxa de lotação, que diminuiu linearmente no decorrer do período de pastejo $\left(\hat{\mathrm{Y}}=7,03-0,067 \mathrm{x} ; \mathrm{R}^{2}=0,67\right.$; $\mathrm{P}=0,0001)$ como resultado da diminuição da TAD $(\mathrm{r}=0,64)$. 
No terço inicial de pastejo, a suplementação não influenciou ( $\mathrm{P}>0,05)$ o ganho médio diário (GMD) dos animais, mas promoveu aumento de $31,5 \%$ na TL. Nesse período, possivelmente houve efeito substitutivo do consumo de suplemento sobre o consumo de forragem. Em pastagens com disponibilidade de forragem não limitante ao consumo e de alto valor nutritivo, onde o animal pode obter quantidade suficiente de nutrientes para o máximo nível de produção individual, o uso de suplementação induz à substituição do consumo de forragem por suplemento sem modificar o aumento diário de peso e com a possibilidade de aumento da taxa de lotação da pastagem (Lange, 1980; Rocha, 1999).

Nos períodos intermediário e final, houve aumento de 52,5 e $160 \%$, respectivamente, no desempenho individual dos animais sob suplementação e ausência de diferença $(\mathrm{P}>0,05)$ na taxa de lotação. A influência positiva sobre o desempenho animal, sem alteração da taxa de lotação, reflete um efeito aditivo da suplementação. Quando o animal obtém quantidade reduzida de nutrientes (forragem pouco palatável, de baixa digestibilidade, pouca disponibilidade ou tempo de pastejo restrito), o fornecimento de suplemento tem pouco efeito no consumo de forragem e

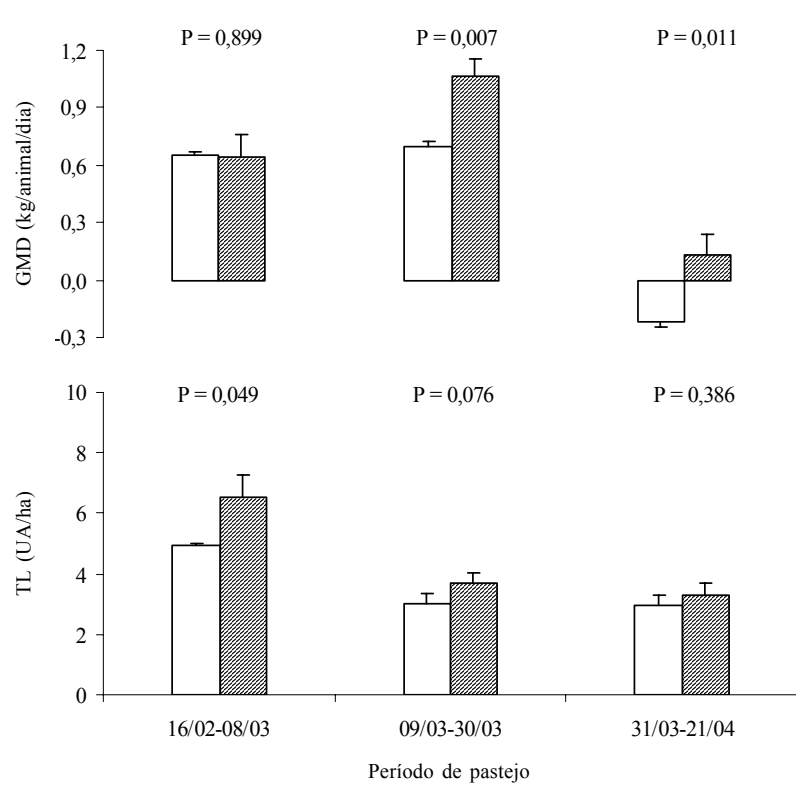

Figura 4 - Ganho médio diário (GMD) de bezerras de corte e taxa de lotação (TL) em pastagem de milheto sem suplementação (colunas sem preenchimento) ou com suplementação energética (colunas com preenchimento). Barras de erro indicam desvio-padrão. promove adição de nutrientes, que, somados ao do pasto, resultam em aumento no consumo total de alimento e melhoram o desempenho dos animais (Lange, 1980; Minson, 1990; Rocha, 1999).

Com massa de forragem e oferta de forragem não limitantes durante o período de pastejo, o principal fator determinante do efeito da suplementação foi a massa de lâminas foliares e sua disposição na estrutura do dossel (Figuras 2 e 3). No início do pastejo, a quantidade de lâminas foliares presentes no pasto permitiu aos animais colherem quantidade suficiente de nutrientes e animais sem suplementação apresentaram desempenho similar aos que receberam suplementação, tendo sido substitutivo - do consumo de pasto por consumo de suplemento - o principal efeito verificado.

A partir do segundo período experimental, no entanto, a modificação estrutural do dossel, com redução da quantidade de lâminas foliares, principalmente nos estratos superiores, não permitiu que fosse obtido, exclusivamente do pasto, o aporte necessário de nutrientes, apesar da manutenção da qualidade da dieta colhida (Santos et al., 2005). No pastejo de forrageiras tropicais maduras, a seletividade animal pode ser superada pela limitação na capacidade de ingestão, em razão da menor quantidade de matéria seca apreendida e, conseqüentemente, do baixo consumo de nutrientes digestíveis por unidade de tempo (Cóser \& Maraschin, 1983). Nesse caso, a utilização de suplemento promoveu desempenho superior, fornecendo aporte adicional de nutrientes, os quais não foram colhidos em quantidade suficiente quando as bezerras permaneceram exclusivamente a pasto. Esses resultados comprovam a importância da mensuração das características estruturais do pasto em ensaios de suplementação animal para promover melhor entendimento da relação planta-animalsuplemento.

\section{Conclusões}

A quantidade e a distribuição de lâminas foliares na estrutura do dossel de milheto (Pennisetum americanum (L.) Leeke) determinam diferentes respostas de bezerras de corte à suplementação energética, como aumento da taxa de lotação suportada pela pastagem em presença de altas quantidades de lâminas foliares e melhora no desempenho individual dos animais quando a participação de lâminas foliares no dossel diminui. $\mathrm{O}$ fornecimento de suplementação energética no nível de $0,9 \%$ do PV para bezerras de corte em pastagem de milheto não interfere nas características produtivas e estruturais do pasto. 


\section{Literatura Citada}

BREMM, C.; ROCHA, M.G.; RESTLE, J. et al. Efeito de níveis de suplementação sobre o comportamento ingestivo de bezerras em pastagem de aveia (Avena strigosa Schreb) e azevém (Lolium multiflorum Lam.). Revista Brasileira de Zootecnia, v.34, n.2, p.319-329, 2005.

CÓSER, A.C.; MARASCHIN, G.E. Desempenho animal em pastagens de milheto comum e sorgo. Pesquisa Agropecuária Brasileira, v.18, n.4, p.421-426, 1983

EMPRESA BRASILEIRA DE PESQUISA E AGROPECUÁRIA EMBRAPA. Sistema brasileiro de classificação de solos. Rio de Janeiro: Centro Nacional de Pesquisas de Solos, 1999. $412 \mathrm{p}$.

FRIZZO, A.; ROCHA, M.G.; RESTLE, J. et al. Produção de forragem e retorno econômico de pastagem de aveia e azevém sob pastejo com bezerras de corte submetidas a níveis de suplementação energética. Revista Brasileira de Zootecnia, v.32, n.3, p.632642, 2003.

GONÇALVES, E.N.; QUADROS, F.L.F. Morfogênese de milheto (Pennisetum americanum (L.) Leeke) em pastejo com terneiras, recebendo ou não suplementação. Ciência Rural, v.33, n.6, p.1123-1128, 2003.

HERINGER, I.; MOOJEN, E.L. Potencial produtivo, alterações da estrutura e qualidade da pastagem de milheto submetida a diferentes níveis de nitrogênio. Revista Brasileira de Zootecnia, v.31, n.2, p.875-882, 2002 (supl.).

HODGSON, J. Variations in the surface characteristics of the sward and short-term rate at herbage intake by calves and lambs. Grass and Forage Science, v.36, p.49-57, 1981.

HODGSON, J. Grazing management. Science into pratice. Essex: Longman, 1990. 203p.

KLINGMANN, D.L.; MILES, S.R.; MOTT, G.O. The cage method for determining consumption and yield of pasture herbage. Journal of Society of Agronomy, v.35, p.739$746,1943$.

LANGE, A. Suplementacion de pasturas para la producción de carnes. 2.ed. Buenos Aires: CREA, 1980. 74p. (Colección Investigación Aplicada).

LUPATINI, G.C.; MOOJEN, E.L.; RESTLE, J. et al. Resposta do milheto (Pennisetum americanum (L.) Leeke) sob pastejo à adubação nitrogenada. Pesquisa Agropecuária Brasileira, v.31, n.10, p.715-720, 1996.

MINSON, D.L. Forage in ruminant nutrition. San Diego: Academic Press, 1990. 483p.

MOOJEN, E.L.; MARASCHIN, G.E. Potencial produtivo de uma pastagem nativa do Rio Grande do Sul submetida a níveis de oferta de forragem. Ciência Rural, v.32, n.1, p.127-132, 2002.
MORAES, A.; MARASCHIN, G.E. Pressões de pastejo e produção animal em milheto cv. comum. Pesquisa Agropecuária Brasileira, v.23 n.2, p.197-205, 1988.

MORENO, J.A. Clima no Rio Grande do Sul. Porto Alegre: Secretária da Agricultura, 1961. 41p.

MOTT, G.O.; LUCAS, H.L. The design, conduct, and interpretation of grazing trials in cultivated and improved pastures. In: INTERNATIONAL GRASSLAND CONGRESS, 6., 1952, Pennsylvania. Proceedings... Pennsylvania: State College Press, 1952. p.1380-1385.

NATIONAL RESEARCH COUNCIL - NRC. Nutrient requirements of beef cattle. 6.ed. Washington, D.C.: National Academy Press, 1984. 90p.

NELSON, C.J.; MOSER, L.E. Plant factors affecting forage quality In: FAHEY JR., G.C. (Ed.) Forage quality, evaluation, and utilization. Nebraska: University of Nebraska, 1994. p.115-154.

PILAU, A.; ROCHA, M.G.; RESTLE, J. Desenvolvimento de novilhas de corte recebendo ou não suplementação energética em pastagem com diferentes disponibilidades de forragem. Revista Brasileira de Zootecnia, v.34, n.5, p.1486-1492, 2005.

PILAU, A.; ROCHA, M.G.; RESTLE, J. Recria de novilhas de corte com diferentes níveis de suplementação energética em pastagem de aveia preta e azevém. Revista Brasileira de Zootecnia, v.33, n.6, p.2104-2113, 2004 (supl. 2).

PRACHE, S.; BECHET, G.; THERIEZ, M. Effects of concentrate supplementation and herbage allowance on the performance of grazing suckling lambs. Grass and Forage Science, v.45, 423429, 1990

ROCHA, M.G. Suplementação a campo de bovinos de corte. In LOBATO, J.F.P.; BARCELLOS, J.O.J.; KESSLER, A.M. (Eds.) Produção de bovinos de corte. Porto Alegre: EDIPUCRS, 1999. p.77-96.

ROCHA, M.G.; RESTLE, J.; FRIZZO, A. et al. Parâmetros produtivos de uma pastagem temperada submetida a alternativas de utilização. Revista Brasileira de Zootecnia, v.33, n.6, p.1386-1395, 2004.

SANTOS, D.T.; ROCHA, M.G.; GENRO, T.C.M. et al. Suplementos energéticos para recria de novilhas de corte em pastagens anuais. Análise econômica. Revista Brasileira de Zootecnia, v.33, n.6, p. 2359-2368, 2004.

SANTOS, D.T.; ROCHA, M.G.; QUADROS, F.L.F. et al. Suplementos energéticos para recria de novilhas de corte em pastagens anuais. Desempenho animal. Revista Brasileira de Zootecnia, v.34, n.1, p.209-219, 2005.

STATISTICAL ANALYSIS SYSTEM - SAS. SAS/STAT user's guide: statistics. 4.ed. Version 6.08. Cary: 1996. 943p.

WILM, H.G.; COSTELO, D.F.; KIPPLE, G.E. Estimating forage yield by the double-sampling methods. Journal of American Society Agronomy, n.36, p.194-206, 1944. 